\title{
Correlation between nonalcoholic fatty liver disease features and levels of adipokines and inflammatory cytokines among morbidly obese individuals
}

\author{
Letícia BALTIERI, Elinton Adami CHAIM, Felipe David Mendonça CHAIM, Murillo Pimentel UTRINI, \\ Martinho Antonio GESTIC and Everton CAZZO
}

\begin{abstract}
Background - Nonalcoholic fatty liver disease (NAFLD) is the commonest hepatopathy worldwide. Objective - To investigate the correlations between NAFLD histopathological features and the levels of adipokines (adiponectin, leptin, and resistin) and circulating inflammatory markers (interleukin-6 [IL-6], interleukin-8 [IL-8], tumor necrosis factor alpha [TNF- $\alpha$ ], and C-reactive protein [CRP]). Methods - This is an exploratory cross-sectional study, which enrolled 19 women with obesity who underwent bariatric surgery. Biochemical characteristics evaluated included the levels of adiponectin, leptin, resistin, IL-6, IL-8, TNF- $\alpha$, and CRP. NAFLD was assessed through histological examination of liver biopsies carried out during the surgical procedures. Results - The mean age of the study group was $37.3 \pm 8.2$ years old; mean BMI was $36.2 \pm 2.5 \mathrm{~kg} / \mathrm{m}^{2}$. Among individuals with liver fibrosis, the levels of IL-8 were significantly higher ( $24.4 \pm 9.7$ versus $12.7 \pm 6.6 ; P=0.016726)$. The intensity of fibrosis presented a significant negative correlation with the levels of adiponectin $(\mathrm{R}=-0.49379 ; P=0.03166)$; i.e. the higher the levels of adiponectin, the lower the intensity of fibrosis. The intensity of steatohepatitis presented a significant negative correlation with the levels of adiponectin $(\mathrm{R}=-0.562321 ; P=0.01221)$; this means that the higher the levels of adiponectin, the lower the intensity of steatohepatitis. Conclusion - Adiponectin levels were inversely correlated with the severity of fibrosis and steatohepatitis, whereas IL-8 levels were higher in individuals with liver fibrosis among individuals with obesity and NAFLD undergoing bariatric surgery. The use of these markers to assess NAFLD may bring significant information within similar populations.

HEADINGS - Obesity. Fatty Liver. Adipokines. Cytokines. Interleukins.
\end{abstract}

\section{INTRODUCTION}

Nonalcoholic fatty liver disease (NAFLD) is the commonest liver disease around the world, with a worldwide prevalence of $25 \%$, according to a recent systematic review conducted by Younossi et al. Its prevalence has presented a significant rise over recent years, as a direct consequence of the obesity and diabetes epidemics, turning into a source of public health concern ${ }^{(1,2)}$. Since it may present more aggressive phenotypes, which lead to severe forms as nonalcoholic steatohepatitis, cirrhosis, and even liver cancer, there are estimates that NAFLD will be the major indication for liver transplantation by 2030 in the United States (US) ${ }^{(3,4)}$.

The pathophysiology of NAFLD is multifactorial and involves several interconnected mechanisms, such as insulin resistance, lipototoxicity, imbalance of inflammatory mediators, endotoxinemia, among others ${ }^{(5)}$. The role of the metabolically active compounds secreted by the adipose tissue and collectively known as adipokines, as well as of many circulating inflammatory mediators and markers, appears to be significant on the pathogenesis of NAFLD, albeit poorly understood to date $e^{(6-8)}$.
Adiponectin, leptin, and resistin are the most studies adipokines. Adiponectin is a hormone released by the adipose tissue, with anti-inflammatory properties such as inhibiting the effects of pro-inflammatory cytokines, mainly tumor necrosis factor alpha and interleukin-6; its circulating levels are usually lower in individuals with obesity ${ }^{(9)}$. Leptin is involved in the regulation of the circadian cycle and satiety in the central nervous system. Its levels are usually higher in individuals with obesity, although its effects are suppressed in this situation due to a phenomenon called leptin resistance; weight loss often leads to a decrease in its levels associated with an increase of its effects ${ }^{(10)}$. Resistin is a pro-inflammatory adipokine whose main properties are inducing inflammation and insulin resistance, angiogenesis, and proliferation of smooth muscle cells ${ }^{(11)}$.

There are several substances produced by immune cells with active metabolic and immunomodulating functions; they are collectively named cytokines and are usually regarded as mediators and markers of the inflammatory process. Interleukin-6 [IL-6] is a glycoprotein released by a number of cells, mainly monocytes, macrophages, lymphocytes, fibroblasts, keratinocytes, endothelial 
cells, and some tumor cells; it is a regulator of the differentiation of CD4+ T-cells and its levels markedly increase in acute inflammation and mildly to moderately in chronic inflammatory conditions ${ }^{(12)}$. Interleukin-8 (IL-8) is a pro-inflammatory cytokine released by macrophages and epithelial cells whose main function is promoting chemotaxis of neutrophils and T-cells ${ }^{(13)}$. The tumor necrosis factor alpha (TNF- $\alpha$ ) is a cytokine produced by macrophages in response to endotoxinemia, inflammation and cancer; higher levels are usually associated with the acute inflammatory response, but are also linked to obesity ${ }^{(14)}$. The $\mathrm{C}$-reactive protein (CRP) is an acute-phase protein secreted by the liver that increases following IL-6 secretion by macrophages and T-cells; its levels are also mildly elevated in chronic inflammation ${ }^{(15)}$.

Since adipokines, cytokines, and inflammatory markers may present clinical relevance to be used targets for the research of novel therapies, diagnosis methods and assessment of severity of NAFLD, the evaluation of their correlations with the histological abnormalities of this disease presents a significant importance.

This study aims to investigate the correlations between NAFLD histopathological features and the levels of adipokines (adiponectin, leptin, and resistin) and circulating inflammatory markers (IL-6, IL-8, TNF- $\alpha$, and CRP).

\section{METHODS}

This is an exploratory cross-sectional study, which enrolled 19 women with obesity who underwent bariatric surgery at a university hospital from January through December 2015. This study underwent evaluation and was approved by the institutional Ethics Review Board under the reference UNICAMP/289.425. Bariatric surgery was indicated according to the National Institutes of Health Consensus Statement criteria ${ }^{(16)}$. The surgical technique used in all of the individuals was the Roux-en-Y gastric bypass (RYGB). Surgery was indicated for individuals who presented obesity for at least five years, with at least two unsuccessful attempts to conservative treatment, with a body mass index (BMI) equal or above 40 $\mathrm{kg} / \mathrm{m}^{2}$, or equal or above $35 \mathrm{~kg} / \mathrm{m}^{2}$ associated with obesity-related comorbidities. The inclusion criteria were: women aged from 18 to 65 years old, which underwent RYGB. The exclusion criteria were: subjects who belonged to vulnerable groups (mentally ill, institutionalized or aged below 18 years old); recent or previous abuse of alcohol; antecedents of viral acute or chronic hepatitis; serologic abnormalities regarding hepatitis $\mathrm{B}$ or $\mathrm{C}$ virus; and previous bile duct obstruction.

All subjects who undergo bariatric surgery at this institution take part in a preoperative weight loss program which lasts 4 to 12 weeks and is comprehended by weekly consultations carried out by a multidisciplinary team. Individuals undergo surgery once a minimal $10 \%$ preoperative weight loss is achieved or since the minimal body mass index (BMI) of $35 \mathrm{~kg} / \mathrm{m}^{2}$ for subjects with obesity-related morbidities or $40 \mathrm{~kg} / \mathrm{m}^{2}$ for those free of comorbidities is reached ${ }^{(17)}$. No liquid or very low-calorie diet was prescribed in the immediate preoperative period to specifically reduce liver fat volume. All the lab examinations were collected on the day immediately prior to the surgical procedure.

Main characteristics regarding demographics and anthropometric parameters were assessed. Biochemical characteristics evaluated included the levels of adiponectin, leptin, resistin, IL-6, IL-8, TNF-A, and CRP, which were determined in the plasma by means of Western-blot analysis (SpectraMax i3, Molecular Devices,
CA, EUA) at a 540-nm-wavelength. These laboratory assays were collected the day prior to surgery in a fasting state.

NAFLD was assessed through histological examination of liver biopsies carried out during the surgical procedures. All the histological examinations were performed by the same pathologist. Liver abnormalities were classified into three categories: 1) steatosis; 2) fibrosis; 3) steatohepatitis. Each category was divided accordingly as absent or present. The severity of each abnormality was stratified into four categories: absent (0), mild (1), moderate (2), or severe (3).

\section{Statistical analysis}

Data were expressed as means \pm standard deviation. For comparison of proportions, chi-square and Fisher's exact tests were carried out. To compare continuous measures between independent or correlated groups, the Mann-Whitney test was used. Spearman's correlation coefficients (values of $\mathrm{R}$ ) were calculated to assess the association between variables and the outcomes analyzed. The values of $\mathrm{R}$ vary from - 1 to 1 ; values next to the extremities signal negative or positive correlations, respectively. The significance level adopted was $5 \%$ ( $P$-value $<0.05)$. For the execution of analysis, it was used Statistic Analysis System (SAS) software for Windows version 9.2.

\section{RESULTS}

The mean age of the study group was $37.3 \pm 8.2$ years old; mean BMI was $36.2 \pm 2.5 \mathrm{~kg} / \mathrm{m}^{2}$. All of the studied individuals presented mild steatosis at the liver biopsy examination. In relation to fibrosis, $15.8 \%$ presented no fibrosis, $63.1 \%$ mild fibrosis, and $21.1 \%$ moderate fibrosis. Regarding liver inflammatorty activity, $36.8 \%$ presented no steatohepatitis, $52.6 \%$ mild steatohepatitis, and $10.6 \%$ moderate steatohepatitis. The main demographic, anthropometric and the distribution of NAFLD features are presented in TABLE 1.

TABLE 1. Characteristics of the study group.

\begin{tabular}{ll}
\hline Age (years) & $37.3 \pm 8.2$ \\
Gender & \\
Female & $19(100 \%)$ \\
Weight $(\mathrm{kg})$ & $94.9 \pm 9.2$ \\
BMI $\left(\mathrm{kg} / \mathrm{m}^{2}\right)$ & $36.2 \pm 2.5$ \\
NAFLD features & \\
Steatosis & \\
mild & $100 \%$ \\
Fibrosis & \\
absent & $15.8 \%$ \\
mild & $63.1 \%$ \\
moderate & $21.1 \%$ \\
Steatohepatitis & \\
absent & $36.8 \%$ \\
mild & $52.6 \%$ \\
moderate & $10.6 \%$ \\
\hline
\end{tabular}

NAFDL: nonalcoholic fatty liver disease; BMI: body mass index. 
Among individuals with liver fibrosis, the levels of IL-8 were significantly higher $(24.4 \pm 9.7$ versus $12.7 \pm 6.6 ; P=0.016726)$; all other variables evaluated did not differ between the individuals with or without fibrosis. TABLE 2 shows the complete comparisons. None of the variables evaluated differed between the individuals with or without steatohepatitis. TABLE 3 details the complete comparisons.

TABLE 2. Comparison between individuals with and without liver fibrosis.

\begin{tabular}{lccc}
\hline & Non-fibrosis & Fibrosis & Value of $\boldsymbol{P}$ \\
\hline Age (years) & $35 \pm 5.3$ & $37.8 \pm 8.7$ & 0.610032 \\
BMI $\left(\mathrm{kg} / \mathrm{m}^{2}\right)$ & $35.8 \pm 1.4$ & $36.3 \pm 2.7$ & 0.767814 \\
Adiponectin & $207.3 \pm 21.5$ & $186.4 \pm 58.3$ & 0.556420 \\
IL-6 (pg/dL) & $39.7 \pm 24$ & $28.5 \pm 17.1$ & 0.336081 \\
IL-8 (pg/dL) & $12.7 \pm 6.6$ & $24.4 \pm 9.7$ & 0.016726 \\
Resistin (pg/dL) & $46.6 \pm 76$ & $51.7 \pm 33.3$ & 0.843854 \\
Leptin $(\mathrm{pg} / \mathrm{dL})$ & $102.8 \pm 31.4$ & $101.1 \pm 29.5$ & 0.92151 \\
TNF- $\alpha(\mathrm{pg} / \mathrm{dL})$ & $315.4 \pm 427.4$ & $105.3 \pm 229.9$ & 0.217523 \\
CRP $(\mathrm{pg} / \mathrm{dL})$ & $63.4 \pm 23.6$ & $71.9 \pm 26.5$ & 0.610032 \\
\hline
\end{tabular}

BMI: body mass index; IL-6: interleukin-6; IL-8: interleukin-8; TNF- $\alpha$ : tumor necrosis factor alpha; CRP: C-reactive protein; pg/dL: picograms per deciliter.

TABLE 3. Comparison between the individuals with and without steatohepatitis.

\begin{tabular}{lccc}
\hline & $\begin{array}{c}\text { Non- } \\
\text { steatohepatitis }\end{array}$ & Steatohepatitis & Value of $\boldsymbol{P}$ \\
\hline Age (years) & $33.7 \pm 4.9$ & $39.4 \pm 9.1$ & 0.147749 \\
BMI $\left(\mathrm{kg} / \mathrm{m}^{2}\right)$ & $35.8 \pm 2.4$ & $36.5 \pm 2.7$ & 0.573183 \\
Adiponectin & $217.1 \pm 28$ & $173.7 \pm 60.3$ & 0.093356 \\
IL-6 (pg/dL) & $31.8 \pm 22.8$ & $29.4 \pm 15.8$ & 0.794518 \\
IL-8 (pg/dL) & $12.6 \pm 5.7$ & $15.6 \pm 9.3$ & 0.445529 \\
Resistin (pg/dL) & $45.2 \pm 37.7$ & $54.2 \pm 42$ & 0.644999 \\
Leptin (pg/dL) & $104.1 \pm 32.5$ & $99.8 \pm 28$ & 0.767814 \\
TNF- $\alpha(\mathrm{pg} / \mathrm{dL})$ & $206.2 \pm 326.7$ & $99 \pm 229.4$ & 0.411142 \\
CRP $(\mathrm{pg} / \mathrm{dL})$ & $72.9 \pm 18.2$ & $69.2 \pm 29.8$ & 0.767814 \\
\hline
\end{tabular}

BMI: body mass index; IL-6: interleukin-6; IL-8: interleukin-8; TNF- $\alpha$ : tumor necrosis factor alpha; CRP: C-reactive protein; pg/dL: picograms per deciliter.

The intensity of fibrosis presented a significant negative correlation with the levels of adiponectin $(\mathrm{R}=-0.49379 ; P=0.03166)$; this means that the higher the levels of adiponectin, the lower the intensity of fibrosis. FIGURE 1 presents graphical representations of the correlation analysis of each variable evaluated with the severity of fibrosis and the respective correlation coefficients and values of P. Similarly, the intensity of steatohepatitis presented a significant negative correlation with the levels of adiponectin $(\mathrm{R}=-0.562321 ; P=0.01221)$; this means that the higher the levels of adiponectin, the lower the intensity of steatohepatitis. None of the other evaluated variables presented significant correlations with the intensities of both fibrosis and steatohepatitis. FIGURE 2 presents graphical representations of the correlation analysis of each variable evaluated with the severity of steatohepatitis and the respective correlation coefficients and values of $P$.

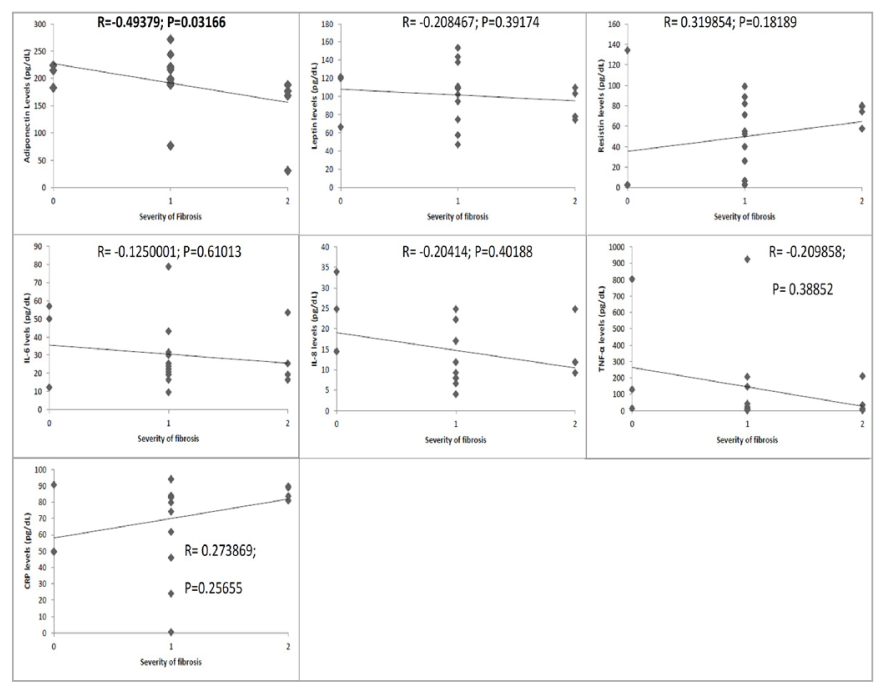

FIGURE 1. Correlations between adipokine/cytokine profiles and severity of fibrosis. IL-6: interleukin-6; IL=8: interleukin-8; TNF- $\alpha$ : tumor necrosis factor alpha; CRP: C-reactive protein; R: coefficient of correlation; $P$ : value of $P$.

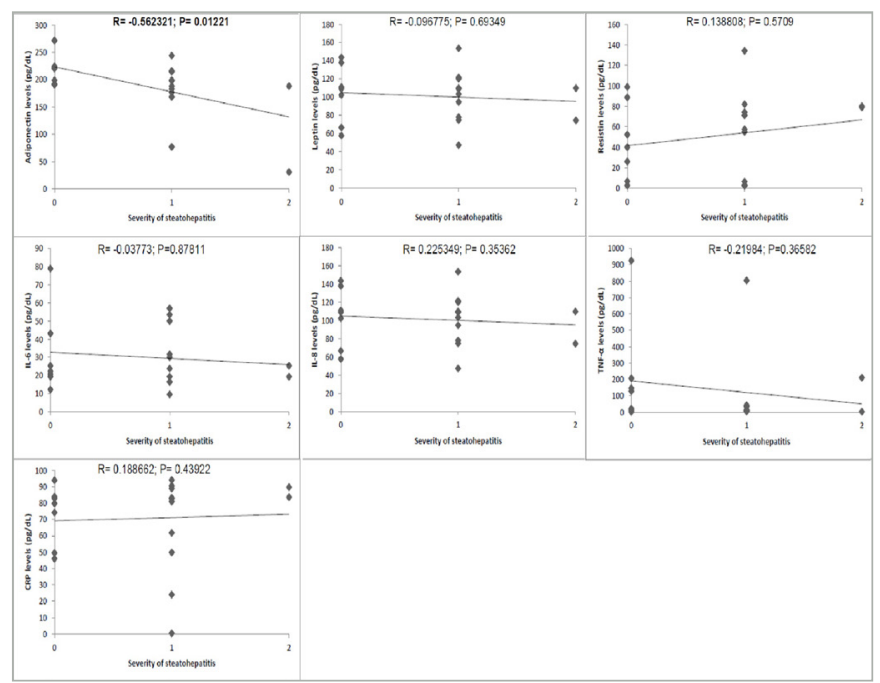

FIGURE 2. Correlations between adipokine/cytokine profiles and severity of steatohepatitis. IL-6: interleukin-6; IL=8: interleukin-8; TNF- $\alpha$ : tumor necrosis factor alpha; CRP: C-reactive protein; R: coefficient of correlation; $P$ : value of $P$.

\section{DISCUSSION}

The interplay between the liver metabolism and circulating levels of active substances with pro or anti-inflammatory properties is a complex pathophysiological process which is not completely understood. However, due to obesity and fatty liver epidemics, the analysis of the role of these compounds presents a great significance as a way to gain insight into the mechanisms of chronic liver injury and plan therapies targeting these molecules or, at least, their use as markers of severity of disease.

The current study showed significant negative correlations between the levels of adiponectin and the severity of both liver fibrosis and steatohepatitis, signaling a protective effect of adiponectin in 
regard to the progression of NAFLD to more aggressive forms. This role may be potentially linked to the anti-inflammatory properties of adiponectin, as well as its insulin sensitizing effect. Both effects are likely to act conjointly to, at least, stabilize the liver injury in the context of NAFLD. The relationship between adiponectin and hepatoprotection has been previously observed in the literature ${ }^{(18-21)}$. Since bariatric surgery leads to increases in the levels of adiponectin $^{(22-25)}$, it is reasonable to suppose that this mechanism is involved to some degree in the significant improvement of NAFLD reported after surgery ${ }^{(26-29)}$.

There is evidence that leptin levels are associated with liver disease ${ }^{(30-32)}$; it is possible that the present study did not show significant correlations because all of the studied individuals presented obesity and thus tended to present high levels. The role of resistin in the development and progression of NAFLD is not so well established and the previous available evidence showed mixed results, with some authors reporting a significant association with NAFLD ${ }^{(33-35)}$, and others demonstrating no differences ${ }^{(36-38)}$. D'Incao et al. have observed that leptin levels were inversely correlated with the degree of steatosis, and also that resistin levels were inversely correlated with fibrosis stages ${ }^{(18)}$.

Higher levels of IL-8 among individuals with liver fibrosis were also observed in the present study. Previous studies have demonstrated that IL-8 is strongly activated in chronic liver disease, thus likely contributing to liver inflammation; Zimmerman et al. ${ }^{(39)}$ suggested a possible role of IL-8 for recruitment and activation of hepatic macrophages. The increased levels of IL-8 among individuals with NAFLD compared to healthy controls have also been demonstrated by Jarrar et al. ${ }^{(40)}$ and Hasanaliyeva et al. ${ }^{(41)}$. The latter study pointed out the IL-8 levels were also independently associated with fibrosis among individuals with NAFLD. There is scarce evidence on the influence of bariatric surgery on IL-8 levels; Klein et al. ${ }^{(42)}$ observed a significant decrease in its levels, thus this may also be involved in the improvement of NAFLD after surgery.

Although CRP, TNF- $\alpha$, and IL-6 did not differ statistically among the studied individuals, there are previous evidence of their significant influence on the NAFLD pathophysiology ${ }^{(43-46)}$. The lack of significance in regards to these markers in the present study may be caused by the small number of individuals analyzed, or by the selection bias due to the high frequency of NAFLD within this population.

This study has some limitations that should be taken into account. Firstly, it was performed in a small patient population; this occurs primarily due to the high costs of the assays utilized in this study. Furthermore, there was not a control group with healthy individuals and all the studied individuals presented some degree of NAFLD, facts that limit a complete explanation of the findings and further extrapolation. The major caveat of this approach is that it is not possible to fully determine which features should certainly be ascribed to which of the three modalities of liver disease considered, as they overlap in the analysis. Finally, the complete inflammatory panel involves a number of mediators which were not analyzed in this study; since there is a complex interplay among these compounds, it may also avoid ultimate conclusions. Despite these caveats, the results of the present study permit significant insights in regards to the progression of liver disease among individuals with obesity and reinforce the possibility of using some of these molecules as markers for diagnosis and following, or even targets for potential therapies.

\section{CONCLUSION}

Adiponectin levels were inversely correlated with the severity of fibrosis and steatohepatitis, whereas IL-8 levels were higher in individuals with liver fibrosis among individuals with obesity and NAFLD undergoing bariatric surgery.

\section{Statement of informed consent}

Informed consent was obtained from all individual participants included in the study.

\section{Statement of human and animal rights}

All procedures performed in studies involving human participants were in accordance with the ethical standards of the institutional and/or national research committee and with the 1964 Helsinki declaration and its later amendments or comparable ethical standards.

Baltieri L, Chaim EA, Chaim FDM, Utrini MP, Gestic MA, Cazzo E. Correlações entre características da doença hepática gordurosa não-alcoólica e os níveis de adipocinas e citocinas inflamatórias em indivíduos submetidos à cirurgia bariátrica. Arq Gastroenterol.

RESUMO - Contexto - A doença hepática gordurosa não-alcoólica (DHGNA) é a hepatopatia mais comum no mundo. Objetivo - Investigar correlações entre as apresentações histopatológicas da DHGNA e os níveis de adipocinas (adiponectina, leptina e resistina) e marcadores sistêmicos de inflamação (interleucina-6 [IL-6], interleucina-8 [IL-8], fator de necrose tumoral alfa [TNF- $\alpha$ ] e proteína C reativa [PCR]). Métodos - Estudo transversal exploratório envolvendo 18 mulheres com obesidade submetidas à cirurgia bariátrica. As características bioquímicas avaliadas incluíram os níveis de adiponectina, leptina, resistina, IL-6, IL-8, TNF- $\alpha$ e PCR. A DHGNA foi avaliada através de exams histológicos de biópsias hepáticas realizadas durantes as cirurgias. Resultados - A idade média foi 37,3 $\pm 8,2$ anos; o índice de massa corporal (IMC) médio foi $36,2 \pm 2,5 \mathrm{~kg} / \mathrm{m}^{2}$ Entre os indivíduos com fibrose hepática, os níveis de IL-8 foram significativamente mais altos $(24,4 \pm 9,7$ versus $12,7 \pm 6,6 ; P=0,016726)$. A intensidade da fibrose apresentou uma correlação negativa significativa com os níveis de adiponectina $(\mathrm{R}=-0,49379 ; P=0,03166)$, demonstranso que, quanto maiores os níveis de adiponectina, menor a intensidade da fibrose. A intensidade da esteato-hepatite apresentou uma correlação negativa significativa com os níveis de adiponectina $(\mathrm{R}=-0,562321 ; P=0,01221)$, demonstrando que quanto mais altos os níveis de adiponectina, menor a intensidade da esteato-hepatite. Conclusão - Os níveis de adiponectina correlacionaram-se negativamente com a severidade da fibrose e da esteato-hepatite, enquanto os níveis de IL-8 foram maiores entre os indivíduos com fibrose hepática. O uso destes marcadores pode trazer informações significativas sobre a DHGNA em populações com obesidade.

DESCRITORES - Obesidade. Fígado gorduroso. Adipocinas. Citocinas. Interleucinas. 


\section{REFERENCES}

1. Younossi ZM, Koenig AB, Abdelatif D, Fazel Y, Henry L, Wymer M. Global epidemiology of nonalcoholic fatty liver disease-Meta-analytic assessment of prevalence, incidence, and outcomes. Hepatology. 2016;64:73-84.

2. Cazzo E, de Felice Gallo F, Pareja JC, Chaim EA. Nonalcoholic fatty liver disease in morbidly obese subjects: correlation among histopathologic findings, biochemical features, and ultrasound evaluation. Obes Surg. 2014;24:666-8.

3. Charlton MR, Burns JM, Pedersen RA, Watt KD, Heimbach JK, Dierkhising RA. Frequency and outcomes of liver transplantation for nonalcoholic steatohepatitis in the United States. Gastroenterology. 2011;141:1249-53.

4. Shaker M, Tabbaa A, Albeldawi M, Alkhouri N. Liver transplantation for nonalcoholic fatty liver disease: new challenges and new opportunities. World J Gastroenterol. 2014;20:5320-30.

5. Cazzo E, Pareja JC, Chaim EA. Nonalcoholic fatty liver disease and bariatric surgery: a comprehensive review. Sao Paulo Med J. 2017;135:277-95.

6. Finelli C, Tarantino G. What is the role of adiponectin in obesity related non-alcoholic fatty liver disease? World J Gastroenterol. 2013;19:802-12.

7. Jamali R, Razavizade M, Arj A, Aarabi MH. Serum adipokines might predict liver histology findings in non-alcoholic fatty liver disease. World J Gastroenterol. 2016;22:5096-103.

8. Hui E, Xu A, Bo Yang H, Lam KS. Obesity as the common soil of non-alcoholic fatty liver disease and diabetes: Role of adipokines. J Diabetes Investig. 2013;4:413-25.

9. Ohashi K, Yuasa D, Shibata R, Murohara T, Ouchi N. Adiponectin as a Target in Obesity-related Inflammatory State. Endocr Metab Immune Disord Drug Targets. 2015;15:145-50.

10. Farooqi IS, O'Rahilly S. 20 years of leptin: human disorders of leptin action. J Endocrinol. 2014;223:T63-70.

11. Abate N, Sallam HS, Rizzo M, Nikolic D, Obradovic M, Bjelogrlic P, Isenovic ER. Resistin: an inflammatory cytokine. Role in cardiovascular diseases, diabetes and the metabolic syndrome. Curr Pharm Des. 2014;20:4961-9.

12. Wolf J, Rose-John S, Garbers C. Interleukin-6 and its receptors: a highly regulated and dynamic system. Cytokine. 2014;70:11-20.

13. Apostolakis S, Vogiatzi K, Amanatidou V, Spandidos DA. Interleukin 8 and cardiovascular disease. Cardiovasc Res. 2009;84:353-60.

14. Hotamisligil GS, Spiegelman BM. Tumor necrosis factor alpha: a key component of the obesity-diabetes link. Diabetes. 1994;43:1271-8.

15. Choi J, Joseph L, Pilote L. Obesity and C-reactive protein in various populations: a systematic review and meta-analysis. Obes Rev. 2013;14:232-44.

16. Gastrointestinal surgery for severe obesity: National Institutes of Health Consensus Development Conference Statement. Am J Clin Nutr. 1992;55(2 Suppl):615S-619S.

17. Chaim EA, Pareja JC, Gestic MA, Utrini MP, Cazzo E. Preoperative multidisciplinary program for bariatric surgery: a proposal for the Brazilian Public Health System. Arq Gastroenterol. 2017;54:70-74.

18. D'Incao RB, Tovo CV, Mattevi VS, Borges DO, Ulbrich JM, Coral GP, et al. Adipokine Levels Versus Hepatic Histopathology in Bariatric Surgery Patients. Obes Surg. 2017;27:2151-8.

19. du Plessis J, van Pelt J, Korf H, Mathieu C, van der Schueren B, Lannoo M, et al. Association of Adipose Tissue Inflammation With Histologic Severity of Nonalcoholic Fatty Liver Disease. Gastroenterology. 2015;149:635-48.e14.

20. Bekaert M, Verhelst X, Geerts A, Lapauw B, Calders P. Association of recently described adipokines with liver histology in biopsy-proven non-alcoholic fatty liver disease: a systematic review. Obes Rev. 2016;17:68-80.

21. Wolfs MG, Gruben N, Rensen SS, Verdam FJ, Greve JW, Driessen A, et al. Determining the association between adipokine expression in multiple tissues and phenotypic features of non-alcoholic fatty liver disease in obesity. Nutr Diabetes. 2015;5:e146.

22. Malin SK, Bena J, Abood B, Pothier CE, Bhatt DL, Nissen S, et al. Attenuated improvements in adiponectin and fat loss characterize type 2 diabetes non-remission status after bariatric surgery. Diabetes Obes Metab. 2014;16:1230-8.

23. Hosseinzadeh-Attar MJ, Golpaie A, Janani L, Derakhshanian H. Effect of weight reduction following bariatric surgery on serum visfatin and adiponectin levels in morbidly obese subjects. Obes Facts. 2013;6:193-202.

24. Illán-Gómez F, Gonzálvez-Ortega M, Orea-Soler I, Alcaraz-Tafalla MS, Aragón-Alonso A, Pascual-Díaz M, et al. Obesity and inflammation: change in adiponectin, C-reactive protein, tumour necrosis factor-alpha and interleukin-6 after bariatric surgery. Obes Surg. 2012;22:950-5.
25. Hindle AK, Edwards C, McCaffrey T, Fu SW, Brody F. Reactivation of adiponectin expression in obese patients after bariatric surgery. Surg Endosc. 2010;24:1367-73.

26. Mummadi RR, Kasturi KS, Chennareddygari S, Sood GK. Effect of bariatric surgery on nonalcoholic fatty liver disease: systematic review and meta-analysis. Clin Gastroenterol Hepatol. 2008;6:1396-402.

27. Bower G, Athanasiou T, Isla AM, Harling L, Li JV, Holmes E, et al. Bariatric surgery and nonalcoholic fatty liver disease. Eur J Gastroenterol Hepatol. 2015;27:755-68

28. Chavez-Tapia NC, Tellez-Avila FI, Barrientos-Gutierrez T, Mendez-Sanchez N, Lizardi-Cervera J, Uribe M. Bariatric surgery for non-alcoholic steatohepatitis in obese patients. Cochrane Database Syst Rev. 2010;(1):CD007340.

29. Cazzo E, Jimenez LS, Pareja JC, Chaim EA. Effect of Roux-en-Y gastric bypass on nonalcoholic fatty liver disease evaluated through NAFLD fibrosis score: a prospective study. Obes Surg. 2015;25:982-5.

30. Polyzos SA, Kountouras J, Mantzoros CS. Leptin in nonalcoholic fatty liver disease: a narrative review. Metabolism. 2015;64:60-78.

31. Polyzos SA, Aronis KN, Kountouras J, Raptis DD, Vasiloglou MF, Mantzoros CS. Circulating leptin in non-alcoholic fatty liver disease: a systematic review and meta-analysis. Diabetologia. 2016;59:30-43.

32. Boyraz M, Cekmez F, Karaoglu A, Cinaz P, Durak M, Bideci A. Serum adiponectin, leptin, resistin and RBP4 levels in obese and metabolic syndrome children with nonalcoholic fatty liver disease. Biomark Med. 2013;7:737-45.

33. Edwards CR, Hindle AK, Latham PS, Fu SW, Brody FJ. Resistin expression correlates with steatohepatitis in morbidly obese patients. Surg Endosc. 2013;27:1310-4.

34. Jiang LL, Li L, Hong XF, Li YM, Zhang BL. Patients with nonalcoholic fatty liver disease display increased serum resistin levels and decreased adiponectin levels. Eur J Gastroenterol Hepatol. 2009;21:662-6.

35. Pagano C, Soardo G, Pilon C, Milocco C, Basan L, Milan G, et al. Increased serum resistin in nonalcoholic fatty liver disease is related to liver disease severity and not to insulin resistance. J Clin Endocrinol Metab. 2006;91:1081-6.

36. Zou CC, Liang L, Hong F, Fu JF, Zhao ZY, et al. Serum adiponectin, resistin levels and non-alcoholic fatty liver disease in obese children. Endocr J. 2005;52:519-24.

37. Polyzos SA, Kountouras J, Polymerou V, Papadimitriou KG, Zavos C, Katsinelos $P$, et al. Vaspin, resistin, retinol-binding protein- 4 , interleukin- $1 \alpha$ and interleukin- 6 in patients with nonalcoholic fatty liver disease. Ann Hepatol. 2016;15:705-14.

38. Magalhães GC, Feitoza FM, Moreira SB, Carmo AV, Souto FJ, Reis SR, et al. Hypoadiponectinaemia in nonalcoholic fatty liver disease obese women is associated with infrequent intake of dietary sucrose and fatty foods. J Hum Nutr Diet. 2014;27(Suppl 2):301-12.

39. Zimmermann HW, Seidler S, Gassler N, Nattermann J, Luedde T, Trautwein $\mathrm{C}$, Tacke F. Interleukin- 8 is activated in patients with chronic liver diseases and associated with hepatic macrophage accumulation in human liver fibrosis. PLoS One. 2011;6:e21381.

40. Jarrar MH, Baranova A, Collantes R, Ranard B, Stepanova M, Bennett C, et al. Adipokines and cytokines in non-alcoholic fatty liver disease. Aliment Pharmacol Ther. 2008;27:412-21.

41. Hasanaliyeva N, Patel K, Guy CD, Gruss HJ, Streilein R, Hall R, et al. IL-8 and MCP1 are Independently Associated with Hepatic Fibrosis in Patients with Nonalcoholic Fatty Liver Disease. Hepatology. 2015;62(S1):1265A.

42. Klein S, Mittendorfer B, Eagon JC, Patterson B, Grant L, Feirt N, et al. Gastric bypass surgery improves metabolic and hepatic abnormalities associated with nonalcoholic fatty liver disease. Gastroenterology. 2006;130:1564-72.

43. Estep M, Abawi M, Jarrar M, Wang L, Stepanova M, Elariny H, et al. Association of obestatin, ghrelin, and inflammatory cytokines in obese patients with non-alcoholic fatty liver disease. Obes Surg. 2011;21:1750-7.

44. Paredes-Turrubiarte G, González-Chávez A, Pérez-Tamayo R, Salazar-Vázquez BY, Hernández VS, Garibay-Nieto N, et al. Severity of non-alcoholic fatty liver disease is associated with high systemic levels of tumor necrosis factor alpha and low serum interleukin 10 in morbidly obese patients. Clin Exp Med. 2016;16: 193-202.

45. García-Galiano D, Sánchez-Garrido MA, Espejo I, Montero JL, Costán G, Marchal T, et al. IL-6 and IGF-1 are independent prognostic factors of liver steatosis and non-alcoholic steatohepatitis in morbidly obese patients. Obes Surg. 2007; 17:493-503.

46. Yeniova AO, Küçükazman M, Ata N, Dal K, Kefeli A, Başyiğit S, et al. High-sensitivity $\mathrm{C}$-reactive protein is a strong predictor of non-alcoholic fatty liver disease. Hepatogastroenterology. 2014;61:422-5. 